\title{
Quantitative assessment of the clinical susceptibility of calcium-sensing receptor polymorphisms in cancer patients
}

This article was published in the following Dove Press journal: Cancer Management and Research

\author{
Haohai Huang' \\ Tao $\mathrm{Li}^{2}$ \\ Dan Liao 3,4 \\ Zhu Zhu ${ }^{4}$ \\ Yong Dong ${ }^{5}$
}

'Department of Science and Education, Dongguan Third People's Hospital, Affiliated Dongguan Shilong People's Hospital of Southern Medical University, Dongguan, Guangdong, China; ${ }^{2}$ Department of Medical Oncology, People's Hospital of Gaozhou, Gaozhou, Guangdong, China; ${ }^{3}$ Department of Gynaecology \& Obstetrics, Dongguan Third People's Hospital, Affiliated Dongguan Shilong People's Hospital of Southern Medical University, Dongguan, Guangdong, China; ${ }^{4}$ China-American Cancer Research Institute, Dongguan Scientific Research Center, Guangdong Medical University, Dongguan, Guangdong, China; ${ }^{5}$ Department of Cancer Center, Dongguan Third People's Hospital, Affiliated Dongguan Shilong People's Hospital of Southern Medical University, Dongguan, Guangdong, China

Correspondence: Yong Dong Department of Cancer Center, Dongguan Third People's Hospital, Affiliated Dongguan Shilong People's Hospital of Southern Medical University, No. I, Huangzhou Xianglong Road of Shilong Town, Dongguan, Guangdong 523326, China

Fax +860769 81368809

Email yongdong8809@163.com
Background: Accumulating evidence has suggested a relationship between calcium-sensing receptor $(C A S R)$ polymorphisms and cancer risk in different types of cancer; however, the findings from epidemiologic studies have been conflicting. The purpose of this meta-analysis was to assess the clinical susceptibility of CASR polymorphisms in cancer patients.

Materials and methods: This study systematically searched MEDLINE and EMBASE databases for eligible articles through March 2017. The strength of association was expressed as odds ratio and $95 \%$ CI. Publication bias, heterogeneity, sensitivity analysis, and subgroup analyses were also examined.

Results: Fourteen related case-control studies were finally identified to be included in the present analysis. The pooled result showed that no significant associations were found among CASR rs1801725, rs1042636, rs12485716, rs4678174, rs1801726, rs17251221, rs10934578, and rs2270916 polymorphisms and cancer risk under all genetic models $(P>0.05)$. The relationship between CASR rs 1801725 polymorphism and risk of cancer was consistent in the subgroup analyses, and robust in sensitivity analysis. No publication bias was presented in our pooled-analysis. Conclusion: The current evidence for our pooled analysis suggests that the CASR polymorphisms are not associated with an increased risk of cancer. Further larger studies are still necessary to warrant and validate the findings in the current meta-analysis.

Keywords: calcium-sensing receptor, polymorphism, cancer, susceptibility, meta-analysis

\section{Introduction}

Cancer remains a major public challenge for health care worldwide, with $\sim 12.7$ million new cancer cases and 7.6 million cancer-related deaths in $2012 .{ }^{1}$ Although the exact mechanism of tumor pathogenesis is not clearly exposed, accumulating evidence supported that both environmental and genetic factors contribute to the etiology of cancer. ${ }^{2}$ The use of single-nucleotide polymorphisms (SNPs) in candidate genes is considered to be an approach to identify novel susceptibility genes for the cancer development. Currently, several epidemiologic studies have indicated that high dietary calcium supplement or high serum calcium may be associated with an increased cancer risk, particularly lethal or advanced disease. ${ }^{3}$

The calcium-sensing receptor (CASR) belongs to the metabotropic glutamate receptor subclass of G-protein-coupled receptors, and is located on chromosome 3p13.3-21. ${ }^{4}$ The central role of CASR in calcium homeostasis was through its regulation of parathyroid hormone (PTH) secretion, as well as calcium re-absorption. ${ }^{5}$ The expression of CASR has previously been reported in bone, parathyroid, and kidney, 
with clear roles in calcium homeostasis. ${ }^{6}$ Further research has demonstrated that the functional expression of CASR was also described in other tissues, including prostate, breast, and colon cancer tissue. Loss and gain of function mutations of CASR shows that changes in calcium ion $\left(\mathrm{Ca}^{2+}\right)$ may mediate by the intracellular signaling. CASR may also influence several tumor-related processes, independent of circulating calcium level regulation. ${ }^{7}$ Evidence from the epidemiologic studies shows that the SNPs in CASR gene related to serum calcium could function as risk markers, which is of importance for the development of diseases. ${ }^{8}$ Moreover, genome-wide association studies (GWAS) have also evaluated gene-environment (ie, SNPs in CASR gene and calcium intake) interactions associated with the risk of cancer. ${ }^{9}$ However, the role of $C A S R$ polymorphisms in cancer susceptibility/incidence is not fully understood, due to the relatively small sample sizes and inconclusive results of these studies. We, therefore, performed the present pooled analysis based on all the published data to shed more light on the impact of $C A S R$ gene polymorphisms in susceptibility to cancer. To assess the prevalence of these SNPs, the influence of cancer types and ethnicity for cancer risk were also examined in the present analysis. The results of our analysis provide new insight that could be recommended for further investigation.

\section{Materials and methods}

\section{Searching strategy}

All relevant studies concerning the associations between the CASR polymorphisms and cancer risk, and published from their inception to April 2016, were identified by comprehensive searches of electronic databases, including Pubmed, EMBASE, Web of Science, China National Knowledge Infrastructure (CNKI), SinoMed, and WanFang databases, without any restrictions. The following search key words and medical subject heading terms were used: (“Calcium-Sensing Receptor" OR “CASR”) AND (“cancer” OR “malignancies" OR “neoplasms” OR “tumor” OR "carcinoma") AND ("polymorphism" OR "variation" OR "variant” OR “single nucleotide polymorphism" OR "mutation" OR “SNP” OR “mutant”). Additionally, reference lists of all the included studies and relevant review articles were also manually searched to identify any eligible studies for inclusion.

\section{Inclusion criteria and exclusion criteria}

The included papers should meet the following criteria: 1) assessment of the relationship between cancer risk and the
CASR polymorphisms; 2) with a case-control study design; and 3 ) detailed genotype frequency of cases and controls were provided directly or could be calculated from the article text. Exclusion criteria were: 1) letters, reviews, or case reports; 2) not concerned with cancer risk; 3 ) overlapping study populations; 4) animal studies; and 5) studies with incomplete data.

\section{Data extraction}

For studies that met our inclusion criteria, the following variables were recorded from each eligible study: the first author's name, year of publication, participant mean age and sex, cancer site, country and ethnicity of the study population, source of control, sample size, number of cases and controls, genotype frequency, and evidence of Hardy-Weinberg equilibrium (HWE) in controls.

\section{Statistical analysis}

Crude odds ratios (ORs) with 95\% CIs between the CASR polymorphisms and cancer risk, based on genotype frequencies, in cases and controls were pooled to measure the strength of the association. The pooled ORs with 95\% CIs were calculated in homozygote model (AA vs BB), heterozygote comparison ( $\mathrm{AB}$ vs $\mathrm{BB}$ ), dominant model ( $\mathrm{AB}+\mathrm{AA}$ vs $\mathrm{BB})$, and recessive model ( $\mathrm{AA}$ vs $\mathrm{AB}+\mathrm{BB})$. Statistical heterogeneity across studies was evaluated by using $I^{2}$ statistics. $I^{2}$ values of $25 \%, 50 \%$, and $75 \%$ were assigned to have a low, moderate, and high degree of heterogeneity, respectively. ${ }^{10}$ The chi-square test was conducted to test the distribution of HWE in controls, and $P<0.05$ indicated disequilibrium of HWE. We then carried out the following subgroup analyses: ethnicity (categorized as North-Americans or Europeans) and cancer types (categorized as colorectal cancer [CRC] or prostate cancer). The subgroup analyses were performed only for the rs 1801725 polymorphism because of the small number of studies for other SNPs. To test the robustness of the results, sensitivity analyses were also performed by removing one study at each turn and examining the influence of each individual study on the overall risk estimate. Publication bias of the studies included was examined by using Begg's funnel plots and Egger's test. ${ }^{11}$ A two-tailed $P<0.05$ was considered statistically significant. All statistical tests were performed using STATA statistical software version 12.0 (StataCorp, College Station, TX, USA).

\section{Results}

\section{Identification of eligible studies}

Figure 1 shows the study selection process. Our systematic literature search yielded a total of 14 articles investigating the 
Potentially relevant reports identified through literature search:

- PubMed, EMBASE, and Web of Science $(n=130)$

- CNKI, SinoMed, and WanFang $(n=26)$

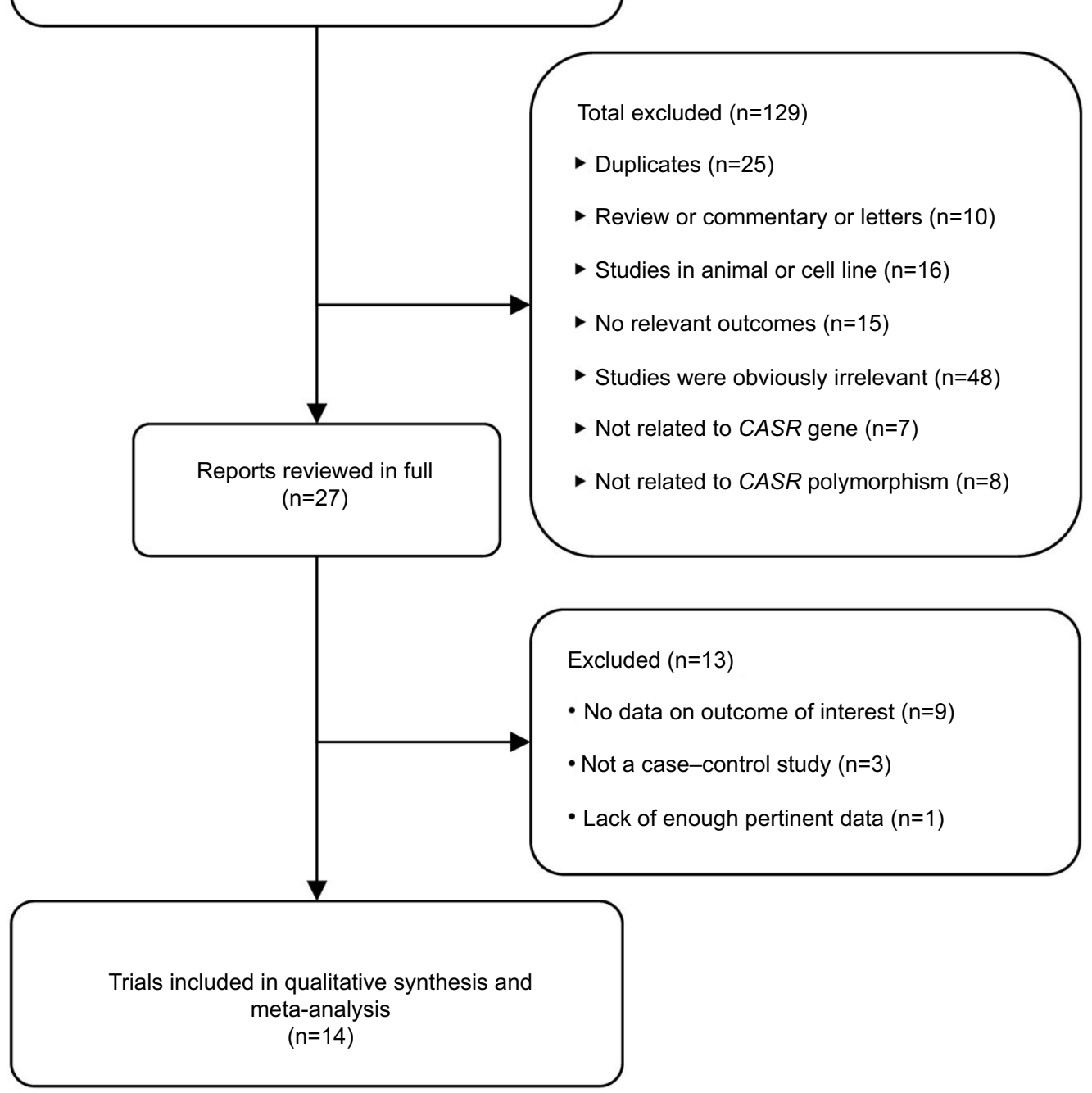

Figure I Flow diagram for identification of relevant studies.

Abbreviation: CASR, calcium-sensing receptor.

associations between the CASR polymorphisms and cancer risk. ${ }^{12-25}$ Based on our highly sensitive search strategy, a total of 156 records were sourced from the initial literature search in PubMed, EMBASE, Web of Science, CNKI, SinoMed, and WanFang databases. We excluded 25 records because they were duplicate studies, and a further 104 articles were also excluded for reasons related to the following: review or commentary or letter $(n=10)$, studies in animal or cell lines $(\mathrm{n}=16)$, no relevant outcomes $(\mathrm{n}=15)$, studies were obviously irrelevant ( $\mathrm{n}=48)$, not related to $C A S R$ gene $(\mathrm{n}=7)$, and not related to $C A S R$ polymorphism $(\mathrm{n}=8)$. After a review of the remaining 27 articles in detail, 14 case-control studies meeting our inclusion criteria were finally selected for the present meta-analysis.

\section{Study characteristics}

The characteristics of the included studies for the relationship of CASR polymorphisms with cancer risk are summarized in Table 1. The publication years ranged from 2002 to 2015 . Of the 14 case-control studies included, an array of cancers, including rectal cancer, ${ }^{12} \mathrm{CRC},{ }^{13-17,21,23}$ pancreatic cancer, ${ }^{20}$ prostate cancer, ${ }^{18,19}$ breast cancer, ${ }^{22}$ ovarian cancer,${ }^{25}$ and hepa- 
Table I Characteristics of all involved studies

\begin{tabular}{|c|c|c|c|c|c|c|c|c|c|}
\hline Authors & Year & $\begin{array}{l}\text { Mean } \\
\text { age }\end{array}$ & $\begin{array}{l}\text { Gender } \\
\text { (M/F) }\end{array}$ & Cancer type & Area & Ethnicity & $\begin{array}{l}\text { Genotype } \\
\text { method }\end{array}$ & $\begin{array}{l}\text { Source of } \\
\text { controls }\end{array}$ & SNPs \\
\hline Speer et $\mathrm{al}^{12}$ & 2002 & 62.5 & $84 / 84$ & Rectal cancer & Hungary & European & PCR-RFLP & $\mathrm{HP}$ & rs 1801725 \\
\hline Fuszek et $\mathrm{al}^{13}$ & 2004 & 65.5 & NA & CRC & Hungary & European & PCR-RFLP & PB & rsl801725 \\
\hline Peters et $\mathrm{al}^{14}$ & 2004 & $>55.0$ & $1002 / 443$ & $\begin{array}{l}\text { Colorectal } \\
\text { adenoma }\end{array}$ & Maryland & $\begin{array}{l}\text { North } \\
\text { America }\end{array}$ & Taqman assay & PB & $\begin{array}{l}\text { rs|80I725; rsI042636; } \\
\text { rs|80I726 }\end{array}$ \\
\hline Dong et $\mathrm{al}^{15}$ & 2008 & 65.0 & $1915 / 1619$ & Colon cancer & USA & $\begin{array}{l}\text { North } \\
\text { America }\end{array}$ & iPLEX Gold & PB & $\begin{array}{l}\text { rsI80I725; rs I042636; } \\
\text { rsI24857I6; rs4678I74; } \\
\text { rsI80I726; rs I0934578; } \\
\text { rs22709I6 }\end{array}$ \\
\hline Bácsi et $a^{16}$ & 2008 & 61.0 & NA & CRC & Hungary & European & PCR-RFLP & PB & rsl801725 \\
\hline Jenab et $\mathrm{al}^{17}$ & 2009 & 58.0 & NA & CRC & Netherlands & European & Taqman assay & PB & rs 1801725 \\
\hline $\begin{array}{l}\text { Schwartz } \\
\text { et al }{ }^{18}\end{array}$ & 2010 & 63.0 & NA & Prostate cancer & USA & $\begin{array}{l}\text { North } \\
\text { America }\end{array}$ & Taqman assay & PB & $\begin{array}{l}\text { rs|80I725; rs1042636; } \\
\text { rs|80I726 }\end{array}$ \\
\hline $\begin{array}{l}\text { Szendroi } \\
\text { et al }{ }^{19}\end{array}$ & 2011 & 67.0 & NA & Prostate cancer & Hungary & European & PCR-RFLP & PB & rs 1801725 \\
\hline $\begin{array}{l}\text { Anderson } \\
\text { et } \mathrm{al}^{20}\end{array}$ & 2013 & 64.0 & $950 / 871$ & Pancreas cancer & Canada & $\begin{array}{l}\text { North } \\
\text { America }\end{array}$ & iPLEX Gold & PB & rs I24857I6; rs4678I74 \\
\hline Kim et $\mathrm{al}^{21}$ & 2013 & $>30.0$ & $797 / 438$ & CRC & Korea & Asian & TaqMan assay & $\mathrm{HP}$ & $\begin{array}{l}\text { rsI24857I6; rs4678I74; } \\
\text { rs10934578; } \\
\text { rs22709I6 }\end{array}$ \\
\hline Li et $\mathrm{a}^{22}$ & 2014 & 45.0 & NA & Breast cancer & China & Asian & TaqMan assay & $\mathrm{HP}$ & rs 17251221 \\
\hline $\begin{array}{l}\text { Mahmoudi } \\
\text { et } \mathrm{al}^{23}\end{array}$ & 2014 & 49.5 & $436 / 424$ & CRC & Iran & Asian & PCR-RFLP & $\mathrm{HP}$ & rs 1801725 \\
\hline Tang et $\mathrm{al}^{24}$ & 2014 & 50.0 & $1406 / 220$ & $\begin{array}{l}\text { Hepatocellular } \\
\text { carcinoma }\end{array}$ & China & Asian & TaqMan assay & $\mathrm{HP}$ & rs $1725|22|$ \\
\hline Yan et $\mathrm{al}^{25}$ & 2015 & 52.58 & NA & Ovarian cancer & China & Asian & PCR-RFLP & $\mathrm{HP}$ & rs 17251221 \\
\hline
\end{tabular}

Abbreviations: SNPs, single-nucleotide polymorphisms; M, male; F, female; NA, not available; HP, hospital-based; PB, population-based; CRC, colorectal cancer; PCR-RFLP, polymerase chain reaction-restriction fragment length polymorphism.

tocellular carcinoma were involved. ${ }^{24}$ Among the included studies, nine studies concerned rs1801725 (A986S), 25-32,36 three studies concerned rs1042636 (R990G), ${ }^{14,15,18}$ three studies concerned rs $12485716,{ }^{15,20,21}$ three studies concerned rs4678174, ${ }^{15,20,21}$ three studies concerned rs 1801726 (Q1100E), ${ }^{14,15,18}$ three studies concerned rs17251221, ${ }^{22,24,25}$ two studies concerned rs10934578, ${ }^{15,21}$ and two studies concerned rs2270916. ${ }^{15,21}$ In all of the included studies, genotype distributions of the CASR polymorphisms in controls were in agreement with HWE, except for one study reported by Kim et $\mathrm{al}^{21}$ in rs2270916 polymorphism. A variety of genotyping methods were applied, including polymerase chain reactionrestriction fragment length polymorphism (PCR-RFLP), Taqman assay, and iPLEX Gold.

\section{Quantitative data synthesis}

For the CASR A986S polymorphism, nine case-control studies with 4844 cases and 5198 controls were identified. Overall, the aggregated results showed that $C A S R$ rs1801725 polymorphism was not significantly associated with cancer risk under the genetic models (the homozygote model: $\mathrm{OR}=0.87,95 \% \mathrm{CI}=0.63-1.18, P=0.36, I^{2}=9.1 \%$ (Figure 2A); the heterozygote comparison model: $\mathrm{OR}=0.85$, 95\% CI $=0.64-1.13, P=0.27, I^{2}=0 \%$ (Figure 2B); the dominant model: $\mathrm{OR}=0.87,95 \% \mathrm{CI}=0.64-1.18, P=0.36, I^{2}=7.6$ (Figure 2C); recessive model: $\mathrm{OR}=0.92,95 \% \mathrm{CI}=0.78-1.09$, $P=0.35, I^{2}=60.3 \%$ (Figure 2D); respectively).

Other polymorphisms of CASR, such as rs1042636, rs12485716, rs4678174, rs1801726, rs17251221, rs10934578, and rs2270916, were mentioned in our systematic literature search relationship of $C A S R$ polymorphisms with cancer risk. The pooled results revealed that $C A S R$ polymorphisms may not increase the risk of cancer under the homozygote model, heterozygote comparison model, dominant model, and recessive model. Table 2 lists the main results of the meta-analysis of the relations between $C A S R$ polymorphisms and cancer susceptibility.

\section{Subgroup analysis}

The associations between $C A S R$ rs1801725 polymorphism and risk of cancer in a subgroup of articles defined according to ethnicity, source of controls, and cancer 
A



C

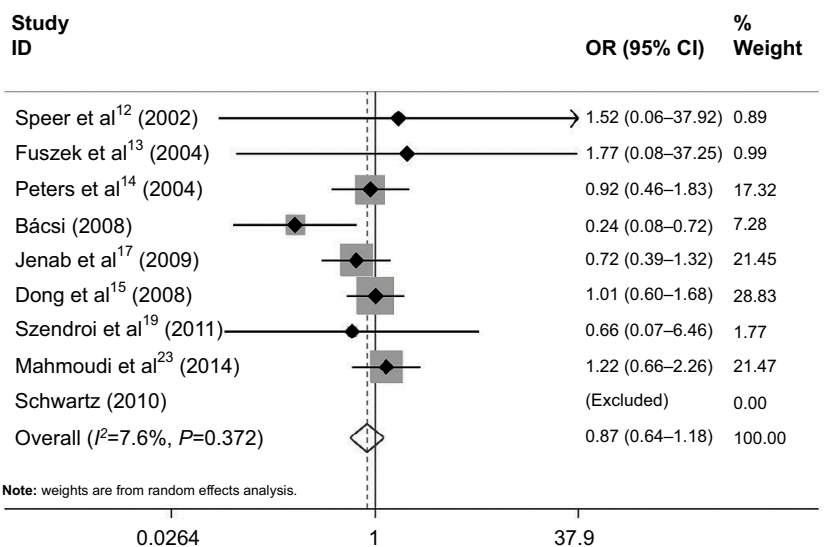

Study

$\%$ ID

OR $(95 \% \mathrm{CI}) \quad$ Weight

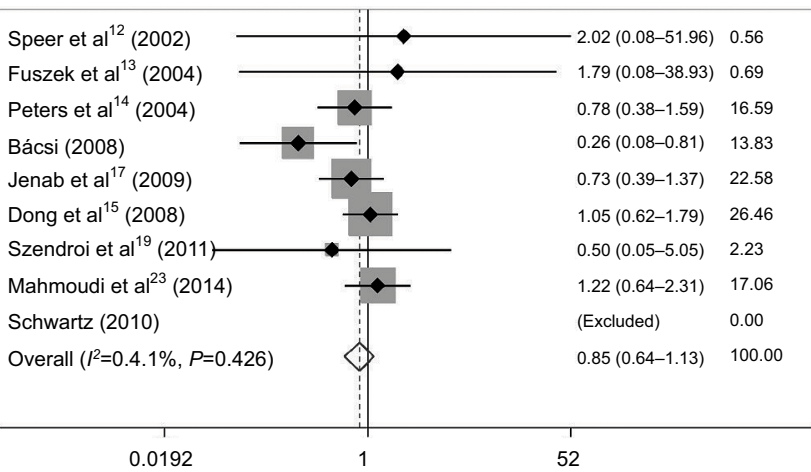

D

Study

$\%$ OR $(95 \% \mathrm{Cl}) \quad$ Weight

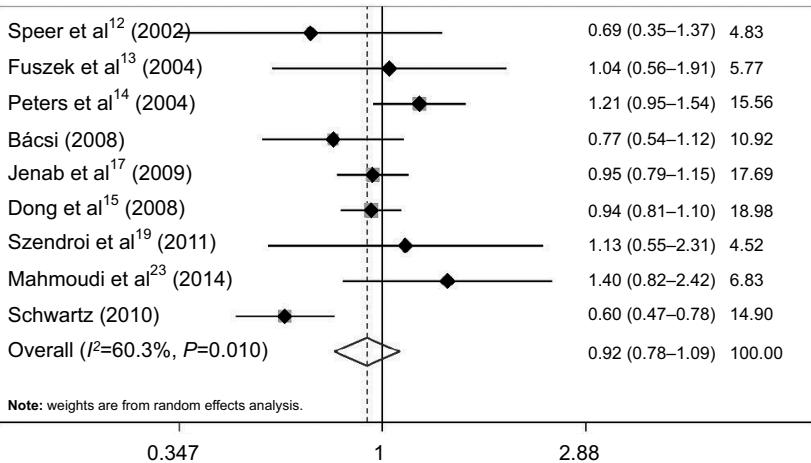

Figure 2 Forest plot of the association between CASR A986S polymorphism and cancer risk: (A) AA vs SS; (B) AS vs SS; (C) AA+AS vs SS; and (D) AA vs AS+SS. Notes: The squares and horizontal lines correspond to the study-specific OR and $95 \% \mathrm{Cl}$. The area of the squares reflects the study-specific weight (inverse of the variance). The diamond represents the pooled $\mathrm{OR}$ and $95 \% \mathrm{Cl}$.

Abbreviations: CASR, calcium-sensing receptor; OR, odds ratio.

type are summarized in Table 3 . The meta-analysis included five studies in Europe ${ }^{15,16,19,20,22}$, and four studies in non-Europe $\mathrm{e}^{17,18,21,26}$. In a subgroup analysis stratified by ethnicity, suggesting that no significant associations were observed between European (homozygote model: $\mathrm{OR}=0.88,95 \% \mathrm{CI}=0.60-1.28$; heterozygote comparison model: $\mathrm{OR}=0.91,95 \% \mathrm{CI}=0.62-1.34$; the dominant model: $\mathrm{OR}=0.88,95 \% \mathrm{CI}=0.60-1.29$; recessive model: $\mathrm{OR}=0.96$, 95\% CI=0.86-1.07) and non-European (homozygote model: $\mathrm{OR}=0.83,95 \% \mathrm{CI}=0.55-1.24$; heterozygote comparison model: $\mathrm{OR}=0.79,95 \% \mathrm{CI}=0.51-1.20$; dominant model: $\mathrm{OR}=0.73,95 \% \mathrm{CI}=0.32-1.63$; recessive model: $\mathrm{OR}=0.87$, $95 \% \mathrm{CI}=0.59-1.30)$ studies. For subgroup analysis of cancer type, we found that no significant associations were observed between the CASR rs1801725 polymorphism and CRC, colon cancer, rectal cancer, colorectal adenoma, and prostate cancer $(P>0.05)$. Subgroup analysis was also carried out with the data segregated by source of controls. The pooled subgroup result showed that no significant associations were observed between the CASR rs 1801725 polymorphism and cancer risk in the hospital-based and population-based control groups under all genetic models.

\section{Publication bias and sensitivity analysis}

No evidence for asymmetry was detected in Begg's funnel plots. The result was also supported by Egger's tests (homozygote model: $P=1.000$; heterozygote comparison model: $P=0.711$; dominant model: $P=1.000$; recessive model: $P=0.754$; respectively). To further test the robustness of the results, we conducted a sensitivity analysis by excluding each study at each turn. The statistical significance of the results was not altered when any single study was omitted (data not shown). 

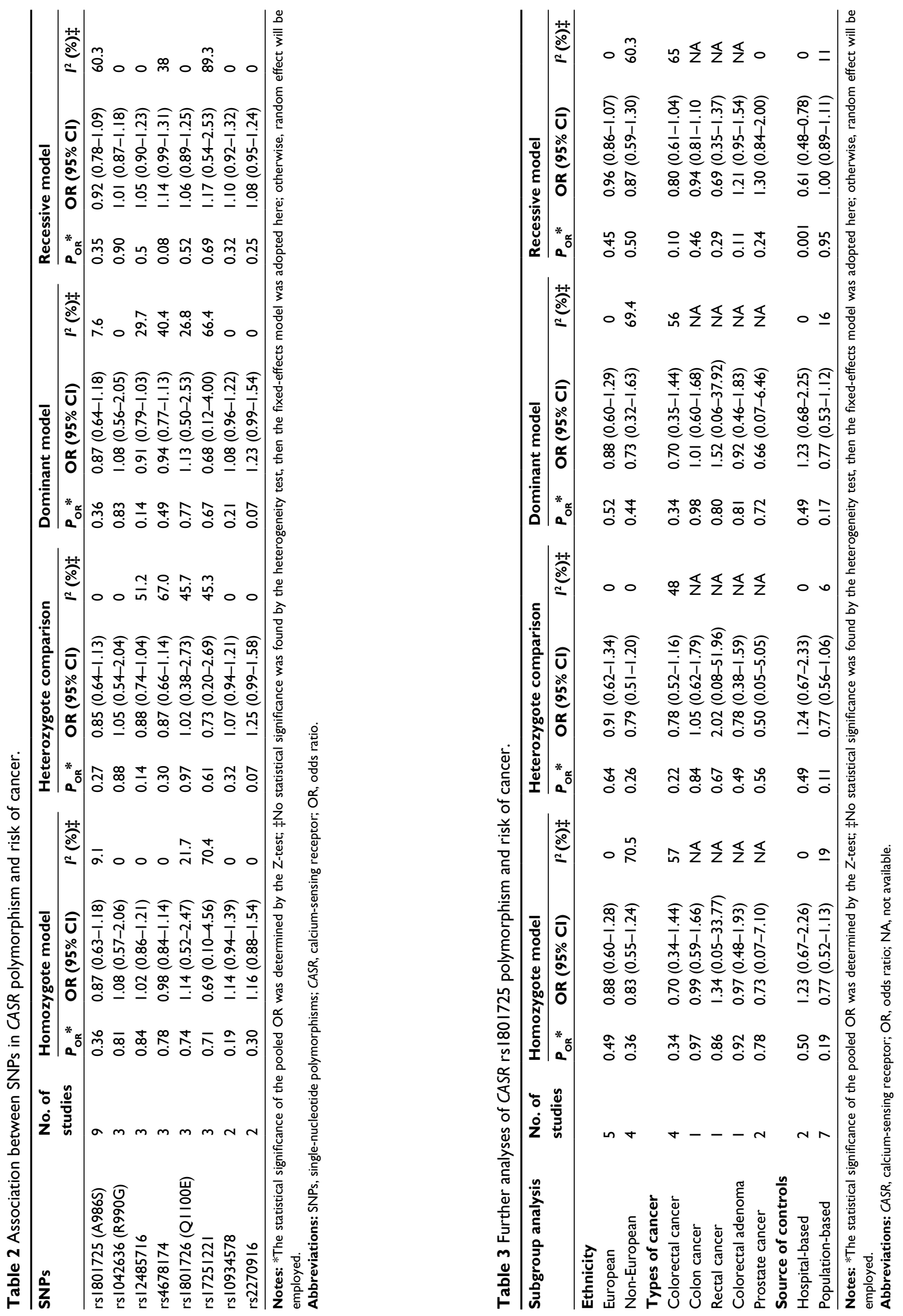


\section{Discussion}

Cancer is a complex multifactorial disease attributed to a disordered balance between proliferation, differentiation, and apoptosis. Evidence from experimental studies suggests that loss in the function of the CASR could accelerate the progression of neoplastic disease. ${ }^{26}$ Many in vitro studies have demonstrated disruptions of the growth suppressing effects of elevated extracellular $\mathrm{Ca}^{2+}$ in intestinal epithelial cells, insulinoma cells, gastrinomas, leydig tumor cells, and in colon carcinoma. ${ }^{27} \mathrm{An}$ increasing body of studies indicates the relationship between CASR activation and high expression and secretion of PTH-related peptide, which is the foremost causal factor in hypercalcemia of malignancy, and a contributor to bone metastatic processes. ${ }^{28}$ Although mutation of the CASR does not appear to be an early event in carcinogenesis, loss or upregulation of normal CASR function can influence several aspects of tumor development. Multiple lines of evidence supported that therapeutic strategies directed at CASR could potentially serve a supportive function in cancer management.

CASR is considered to be an important element of the signaling pathway in mediating the anticancer activities of calcium on cancer development. Previous studies have suggested that calcium may protect against CRC risk through binding to the CASR, or indirectly by binding bile acids and free fatty acids in the colonic lumen, which leads to the induction of tumor cell apoptosis and differentiation. ${ }^{29}$ Calcium activates cell growth, and differentiation through certain signaling pathways that participate in CASR is considered the likely pathway. It promotes E-cadherin expression and the suppression of $\beta$-catenin activation, and possibly modulates the activation of the $\mathrm{p} 38$ mitogen-activated protein kinase cascade system. ${ }^{30}$ Further research has demonstrated that this stimulation is mediated by filamin-A, which can be bound to the A986S mutation site of CASR.$^{31}$ The abnormal expression of CASR may be associated with differentiation and tumor development. ${ }^{32}$ The patterns of CASR expression indicate its role in the pathogenesis of CRC; the high expression of CASR is found in normal large intestinal epithelium, yet is lower in well-differentiated CRC tissue, and is decreased in undifferentiated carcinomas. ${ }^{33}$ Actually, downregulation of the CASR expression in the colonic epithelium is the main element in the pathogenesis of CRC. ${ }^{34}$ Furthermore, epigenetic inactivation of $C A S R$, such as $C A S R$ methylation, has a key role in colorectal carcinogenesis. ${ }^{35}$ However, the influence of these variants on CASR protein function is not clarified.
Up to now, the reported CASR contains several polymorphisms in cancer risk with unknown clinical significance and values. To provide a comprehensive and reliable conclusion, we performed a comprehensive systematic review and meta-analysis to assess the association between eight extensively studied polymorphisms (rs1801725, rs17251221, rs1042636, rs12485716, rs4678174, rs1801726, rs10934578, and rs2270916) and cancer risk reported until April 2016. The pooled results demonstrated that no significant associations were found between the CASR polymorphisms and cancer risk in any of the genetic models in overall analysis. Our results were very robust, which did not vary materially, in spite of the sensitivity analyses and subgroup analysis performed. Moreover, no publication bias was presented in our present meta-analysis.

A previous meta-analysis based on the same topic has been performed by Jeong et al. ${ }^{36}$ Our study has several advantages over this previous meta-analysis to make it more conclusive. First, our meta-analysis included only case-control trials, which was highly homogeneous and less selective risk. Second, previously defined key subgroup analyses based on ethnicity, types of cancer, and source of controls were performed to investigate the impact of various parameters on the pooled outcomes, unlike previously. Our meta-analysis, which includes 14 case-control studies, did not reveal any significant associations for all genetic models, even when stratified analysis was conducted according to ethnicity, ethnicity, types of cancer, and sources of controls. Third, the association between the eight polymorphisms (rs1801725, rs1042636, rs12485716, rs4678174, rs1801726, rs17251221, rs10934578, and rs2270916) in the CASR gene and cancer risk under all genetic models have been investigated in our present analysis, which may provide a comprehensive and reliable conclusion. Finally, sensitivity analyses were also performed to assess the stability of the results; namely, a single study in the meta-analysis which was deleted each time to reflect the influence of the individual data set to the pooled OR. All of the results of the subgroup analysis and sensitivity analysis suggest that the data in this meta-analysis are relatively stable and statistically robust.

Several studies quantifying the genetic effect of $C A S R$ rs 1801725 variant on the susceptibility and prognosis of colorectal, colon or rectal cancer have shown inconsistent results. ${ }^{13-17,21,23}$ A common alanine (A) to serine (S) polymorphism of amino acid 986 in intracellular C-terminal tail of the CASR revealed that A986S plays an important role in maintaining calcium homeostasis. The " $G$ " or " $A$ " allele was 
associated with higher circulating PTH and calcium concentrations when compared with the " $T$ " or "S" allele. ${ }^{37}$ These data support the hypothesis that the mutations in the CASR gene rs1801725 variant are contributed to pathogenesis of CRC. In a subgroup analysis stratified by cancer type (CRC vs prostate cancer), we failed to find any significant association between the CASR rs1801725 polymorphism and the $\mathrm{CRC}$ risk. The relationship was consistent in prostate cancer. Future large-scale, well-designed studies are needed to get a deeper insight into the association.

Some potential limitations in our present meta-analysis should be taken into account. First, we pooled the data using unadjusted information, and other factors (ie, age, family history, the interactions among gene-gene, and even geneenvironment) may potentially impact on our results and result in heterogeneity. Second, for CASR rs1042636, rs 12485716 , rs4678174, rs1801726, rs17251221, rs10934578, and rs2270916 polymorphisms and risk of cancer, considering the limited number and sample sizes of the included studies (only two or three studied), additional studies or a database on these topics are needed. Third, because of the limited data of the reviewed studies, we failed to capture the data of serum levels of calcium intake, which could affect our present study. Fourth, accumulating evidence has suggested that the CASR plays a critical role in bone metastasis. Due to the lack of original data of the included studies, we did not evaluate the effects of CASR in bone metastasis in cancer patients; further studies based on this topic are needed. Finally, the analysis was only based on published data, and no unpublished data were included. Hence, some inevitable publication biases might have a potential impact on our results.

\section{Conclusion}

In summary, our analysis provides reliable evidence that the CASR polymorphisms may not be associated with overall cancer susceptibility under the current published studies. Our subgroup analysis further indicated that the CASR rs 1801725 polymorphism is not associated with an increased risk of CRC and prostate cancer. Large-scale and well methodologically designed studies should be conducted to explore the real relationship between $C A S R$ variants and cancer risk.

\section{Acknowledgments}

The authors thank Dr Guangzho Chen, Department of Pharmacy, Guangdong Province Agricultural Reclamation Central Hospital, for his data analyses and valuable discussions. Funding was provided by departmental sources.

\section{Disclosure}

The authors report no conflicts of interest in this work.

\section{References}

1. Siegel R, Ma J, Zou Z, Jemal A. Cancer statistics, 2014. CA Cancer J Clin. 2014;64(1):9-29.

2. Pharoah PD, Dunning AM, Ponder BA, Easton DF. Association studies for finding cancer-susceptibility genetic variants. Nat Rev Cancer. 2004;4(11):850-860.

3. Huncharek M, Muscat J, Kupelnick B. Colorectal cancer risk and dietary intake of calcium, vitamin $\mathrm{D}$, and dairy products: a metaanalysis of 26,335 cases from 60 observational studies. Nutr Cancer. 2009;61(1):47-69.

4. Cifuentes M, Rojas CV. Antilipolytic effect of calcium-sensing receptor in human adipocytes. Mol Cell Biochem. 2008;319(1-2):17-21.

5. Xie R, Tang B, Yong X, Luo G, Yang SM. Roles of the calcium sensing receptor in digestive physiology and pathophysiology (review). Int $J$ Oncol. 2014;45(4):1355-1362.

6. Abukawa H, Mano H, Arakawa T, Hakeda Y, Kimura H, Kumegawa M. Tissue specific expression and differential regulation by 1alpha,25dihydroxyvitamin D3 of the calcium-sensing receptor (CaSR) gene in rat kidney, intestine, and calvaria. Cytotechnology. 2001;35(1):81-86.

7. Liao J, Schneider A, Datta NS, McCauley LK. Extracellular calcium as a candidate mediator of prostate cancer skeletal metastasis. Cancer Res. 2006;66(18):9065-9073.

8. Ward BK, Magno AL, Walsh JP, Ratajczak T. The role of the calciumsensing receptor in human disease. Clin Biochem. 2012;45(12):943-953.

9. Skinner HG, Schwartz GG. A prospective study of total and ionized serum calcium and fatal prostate cancer. Cancer Epidemiol Biomarkers Prev. 2009;18(2):575-578.

10. Higgins JP, Thompson SG, Deeks JJ, Altman DG. Measuring inconsistency in meta-analyses. BMJ. 2003;327(7414):557-560.

11. Egger M, Davey Smith G, Schneider M, Minder C. Bias in meta-analysis detected by a simple, graphical test. BMJ. 1997;315(7109):629-634.

12. Speer G, Cseh K, Mucsi K, et al. Calcium-sensing receptor A986S polymorphism in human rectal cancer. Int J Colorectal Dis. 2002;17(1):20-24.

13. Fuszek P, Lakatos P, Tabak A, et al. Relationship between serum calcium and CA 19-9 levels in colorectal cancer. World J Gastroenterol. 2004;10(13):1890-1892.

14. Peters U, Chatterjee N, Yeager M, et al. Association of genetic variants in the calcium-sensing receptor with risk of colorectal adenoma. Cancer Epidemiol Biomarkers Prev. 2004;13(12):2181-2186.

15. Dong LM, Ulrich CM, Hsu L, et al. Genetic variation in calcium-sensing receptor and risk for colon cancer. Cancer Epidemiol Biomarkers Prev. 2008;17(10):2755-2765.

16. Bácsi K, Hitre E, Kosa JP, et al. Effects of the lactase $13910 \mathrm{C} / \mathrm{T}$ and calcium-sensor receptor A986S G/T gene polymorphisms on the incidence and recurrence of colorectal cancer in Hungarian population. BMC Cancer. 2008;8:317.

17. Jenab M, McKay J, Bueno-de-Mesquita HB, et al. Vitamin D receptor and calcium sensing receptor polymorphisms and the risk of colorectal cancer in European populations. Cancer Epidemiol Biomarkers Prev. 2009;18(9):2485-2491.

18. Schwartz GG, John EM, Rowland G, Ingles SA. Prostate cancer in African-American men and polymorphism in the calcium-sensing receptor. Cancer Biol Ther. 2010;9(12):994-999.

19. Szendroi A, Speer G, Tabak A, et al. The role of vitamin D, estrogen, calcium sensing receptor genotypes and serum calcium in the pathogenesis of prostate cancer. Can J Urol. 2011;18(3):5710-5716.

20. Anderson LN, Cotterchio M, Knight JA, Borgida A, Gallinger S, Cleary SP. Genetic variants in vitamin d pathway genes and risk of pancreas cancer; results from a population-based case-control study in Ontario, Canada. PloS One. 2013;8(6):e66768.

21. Kim KZ, Shin A, Kim J, et al. Association between CASR polymorphisms, calcium intake, and colorectal cancer risk. PloS One. 2013;8(3):e59628. 
22. Li X, Kong X, Jiang L, et al. A genetic polymorphism (rs17251221) in the calcium-sensing receptor is associated with breast cancer susceptibility and prognosis. Cell Physiol Biochem. 2014;33(1):165-172.

23. Mahmoudi T, Karimi K, Arkani M, et al. Parathyroid hormone gene rs6256 and calcium sensing receptor gene rs1801725 variants are not associated with susceptibility to colorectal cancer in Iran. Asian Pac J Cancer Prev. 2014;15(15):6035-6039.

24. Tang Q, Zhao Y, Wang Y, Wei M. A genetic variant (rs17251221) in the calcium-sensing receptor relates to hepatocellular carcinoma susceptibility and clinical outcome treated by transcatheter hepatic arterial chemoembolization (TACE) therapy. Med Oncol. 2014;31(11):267.

25. Yan S, Yuan C, Yang Q, et al. A genetic polymorphism (rs17251221) in the calcium-sensing receptor is associated with ovarian cancer susceptibility. Oncol Rep. 2015;34(4):2151-2155.

26. Rodland KD. The role of the calcium-sensing receptor in cancer. Cell Calcium. 2004;35(3):291-295.

27. Justinich CJ, Mak N, Pacheco I, et al. The extracellular calcium-sensing receptor (CaSR) on human esophagus and evidence of expression of the CaSR on the esophageal epithelial cell line (HET-1A). Am J Physiol Gastrointest Liver Physiol. 2008;294(1):G120-129.

28. Tfelt-Hansen J, Brown EM. The calcium-sensing receptor in normal physiology and pathophysiology: a review. Crit Rev Clin Lab Sci. 2005;42(1):35-70.

29. Van der Meer R, Kleibeuker JH, Lapre JA. Calcium phosphate, bile acids and colorectal cancer. Eur J Cancer Prev. 1991;1(Suppl 2):55-62.

30. Hobson SA, Wright J, Lee F, McNeil SE, Bilderback T, Rodland KD. Activation of the MAP kinase cascade by exogenous calcium-sensing receptor. Mol Cell Endocrinol. 2003;200(1-2):189-198.
31. Hjalm G, MacLeod RJ, Kifor O, Chattopadhyay N, Brown EM Filamin-A binds to the carboxyl-terminal tail of the calcium-sensing receptor, an interaction that participates in CaR-mediated activation of mitogen-activated protein kinase. J Biol Chem. 2001;276(37): 34880-34887.

32. Chakrabarty S, Radjendirane V, Appelman H, Varani J. Extracellular calcium and calcium sensing receptor function in human colon carcinomas: promotion of E-cadherin expression and suppression of beta-catenin/ TCF activation. Cancer Res. 2003;63(1):67-71.

33. Sheinin Y, Kallay E, Wrba F, Kriwanek S, Peterlik M, Cross HS. Immunocytochemical localization of the extracellular calcium-sensing receptor in normal and malignant human large intestinal mucosa. $J$ Histochem Cytochem. 2000;48(5):595-602.

34. Rogers AC, Hanly AM, Collins D, Baird AW, Winter DC. Review article: loss of the calcium-sensing receptor in colonic epithelium is a key event in the pathogenesis of colon cancer. Clin Colorectal Cancer. 2012;11(1):24-30.

35. Hizaki K, Yamamoto H, Taniguchi H, et al. Epigenetic inactivation of calcium-sensing receptor in colorectal carcinogenesis. Mod Pathol. 2011;24(6):876-884.

36. Jeong S, Kim JH, Kim MG, et al. Genetic polymorphisms of CASR and cancer risk: evidence from meta-analysis and HuGE review. Onco Targets Ther. 2016;9:655-669.

37. Marz W, Seelhorst U, Wellnitz B, et al. Alanine to serine polymorphism at position 986 of the calcium-sensing receptor associated with coronary heart disease, myocardial infarction, all-cause, and cardiovascular mortality. J Clin Endocrinol Metab. 2007;92(6):2363-2369.
Cancer Management and Research

\section{Publish your work in this journal}

Cancer Management and Research is an international, peer-reviewed open access journal focusing on cancer research and the optimal use of preventative and integrated treatment interventions to achieve improved outcomes, enhanced survival and quality of life for the cancer patient The manuscript management system is completely online and includes

\section{Dovepress}

a very quick and fair peer-review system, which is all easy to use. Visit http://www.dovepress.com/testimonials.php to read real quotes from published authors. 